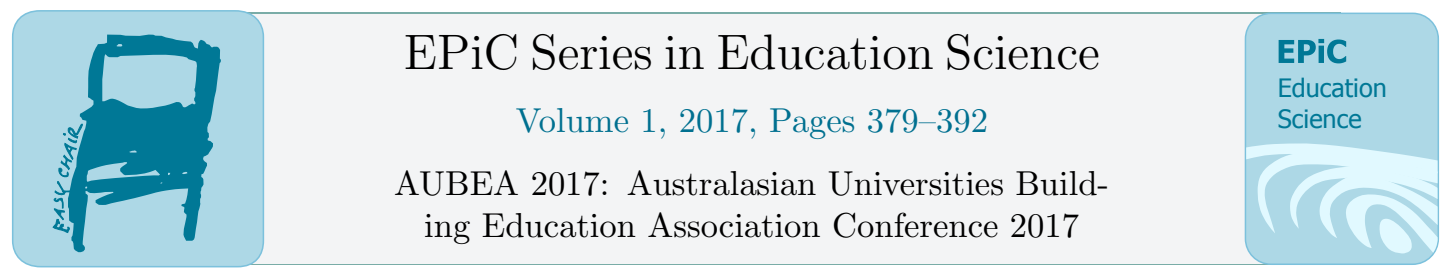

\title{
SIGNIFICANCE OF CULTURE AND EDUCATION IN DEVELOPING SMART VILLAGES IN INDIA
}

V. I. Katharpi' ${ }^{1}$ Dr H. Doloi ${ }^{2}$, Dr D. Week ${ }^{3}$.

${ }^{1}$ Research Graduate, Faculty of Architecture, building and Planning, MSD, University of Melbourne

${ }^{2}$ Professor of Construction management, Faculty of Architecture, building and Planning, MSD, University of Melbourne

${ }^{3}$ Post-Doctoral Fellow, Faculty of Architecture, building and Planning, MSD, University of Melbourne

vkathar@student.unimelb.edu.au

\section{ABSTRACT}

Over $69 \%$ of Indian population that live across 0.6 million villages represent a significant part of Indian Society. However, little has been planned and invested in villages as compared to the urban areas. The fact that villages share only a little less than a quarter of the India's GDP tells us about the lost potential. The sheer numbers are enough to hold as a good argument for planning and dedicated research and investment in this sector. In an effort to empower these rural communities for living with their potentials and contributing positively to the national economy, the creation of the smart villages would not only affect the future of settlements but also force significant changes in the lifestyle in the rural areas. Investigating the elements of the character of the villages and sense of belongingness to the community, this research aims to 
develop a framework for providing necessary education on the impacts on the vernacular characters of the place while promoting development, sustainability and affordability in the hills of Assam. The next few pages would briefly explain the essential and interdependent components that are part of a smart village, before elaborating on a typical rural house and its cultural elements that are architecturally displayed in the layout and use of spaces by the occupants. This research is only part of understanding the role and significance of culture and community as essential factors for developing rural and remote areas that would be socially acceptable.

Keywords: Components, Cultural value, Education, House, Smart Villages.

\section{INTRODUCTION}

It is not a new trend, where people move towards what is more attractive and popular. What is the next best thing? Which is the next best city to live in? Which is the newest technology? And somewhere in this chase the ones who can afford it, are moving out of villages and rarely coming back and those who cannot are stuck in time, where things are rarely changing around them. In rare occasions that people do return and try to bring something back with them, the new trend does not suit the rural lifestyle, and it either the trend disappears, or it changes the village irreversibly.

There is a commercial wave or a cultural wave that is encouraged as it provides what the inhabitants of the village with opportunities, in the form of trade, entertainment, cultural exchange, socialising, etc. but with this metaphorical wave, some things are lost with the change, such as the quiet and tranquil lifestyle of the country side, or the familiarity or comfort of being at home. As if being part of a smooth sailing boat, where there is a system to how things are 
run, but with introduction of new equipment or technology, some sub-systems of the main system become redundant or recessive. In such a wave, the village that held an identity through its lifestyle re-identifies it, or in some unfortunate cases, loses it completely and becomes either a ghost village, where most of the youth are in urban areas earning their livelihood, trying to settle down there, while only the elderly, the disabled, women and children stay behind, or becomes just another village that could be any village anywhere.

The hill regions of Assam is such an example of a remote area where even the main head quarter of the district is quite remote or not as urbanised as compared to other towns in the state of Assam. This is demonstrated when one looks up at the sky at night, and you can actually see stars from the roof of the house in the middle of the town, just as you would see from the middle of the agricultural lands a few kilometres out from the main city of Guwahati, Assam.

In this instance, the lack of pollution is actually a valuable asset for the remote areas which come under threat when the wave of urbanisation comes along. Between Urban areas and Rural areas there are both pros and cons to the way of living, and meeting halfway, where villagers do not relocate for better jobs or do not let the modern progress become a pollution to their remote villages, can be a solution for Smart villages. Having a standard understanding of the smart village concept does not cater to the diversity of different backgrounds with different topographies and cultural contexts within one state or country.

\section{LITERATURE SURVEY}

Smart Villages concept started as off-grid communities that do not rely on the national grid for their energy resource, and it can came to mean more as they took the opportunity to educate, finance and 
mobilise people of remote rural areas by providing them with opportunities as everyone else, including community involvement and training with long term sustainable solutions. (Cambridge, 2014). Inspired by Gandhian philosophy and thoughts, a SmartVillages Project was conceived for the Indian context. By using the word 'Smart' as an acronym for the definition of the concept, where $S=$ Social, Skilled and simple, $M=$ Moral, Methodical and Modern, $\mathrm{A}=$ Aware, Adaptive and Adjusting, $\mathrm{R}=$ Responsive and Ready, and $\mathrm{T}=$ Tech-Savvy and Transparent, an initiative was launched towards mass movement driven by communities with the help of Information technology as the base on which other opportunities could grow.(Samanvay.Com)

As part of an initiative for tourism, the inhabitants of the Mawlynnong Village in Meghalaya, India, came together as a community to ensure that their surroundings and environment would be clean and even won the status of being the cleanest village in Asia in 2003.(Pasricha, 2014) The importance of community driven initiatives or community based contracting is further highlighted in the examples of the 650 schools rebuilt in 8 months by the community in Timor Leste ESRP, and the construction of Boat repair shops, Proper Drainage systems, Water supply and Culvert of streams as part of the Indonesia LOGICA in Aceh, post Tsunami where around 200 villages were affected.(Week, 2016) To tackle the rural-urban migration that left the village of Hudli, Karnataka, India without its youth, poor, deserted and unemployed; supported by the Khadigram established in 1937 by M. Gandhi, a website for buying pickles made by the women of the village to generate income and employment among women. (TheHudliProject, 2017)

These are obvious examples that along with the state participation in the form of resources, policy-making and management, the participation of the villagers is just as important towards the success of the Smart Villages Initiative. There is a need to generate 
awareness and enthusiasm from both parties. The added bonus of doing something for your own community along with your community is driving force that enables communities to progress.

Edward Stack's description of the life and traditions of the Karbi community in the book The Mikirs, edited by Sir Charles Lyall, gives an insight to how the people and the life was in the Mikir Hills of Assam in 1884-86. His notes included images and photographs of people in the cultural attire, house and also a plan of a typical Karbi House, along with descriptions of festivals, funeral proceedings and folklore and stories. Translation and explanation of the grammar and dictionary of the language spoken by the community further displayed the social structure and hierarchy of relations within the community. Sir Charles Lyall's involvement in compiling Stack's Jottings and notes included learning the language as well as treading the same journey as Stack, for the best translation possible of the knowledge that Stack had collected over his time in Assam. Sir Lyall also compared the noted to accounts from three other people who were acquainted with the tribe, which were not detailed but did concur with the observations made by Stack. The account recorded and compiled in the book gives a reference picture from where we compare and analyse the changes in the community since then.(Edward Stack, 1908)

Roger barker's theory of behaviour settings is used to explain small-scale social systems, as well as the study of behaviour in its natural environment. Though it is mainly used for research areas regarding psychology, environment and behaviour, the theory can be further applied to understand a community depending on the environment that they have built or maintained around them. Factors that seem to surface from the study would be the key indicators to communicate the translation of the cultural significance of an artefact or practice.(Schoggen, 1989) 


\section{RESEARCH METHOD}

The Research involves two kinds of methods, where in one, there is an active participation of the community to express their needs as they see fit, and in the other, the study of a traditional house gives insight to the culture and understanding how the customs and traditions of the people of the house have influenced the way the space is built and used.

1) As part of the Conference held at Assam Engineering College, Guwahati, Assam, all the students of the college who attended the 4day workshop were asked to participate and define "smart village" and mention what components or issues would be required to tackle to achieve a smart village.(Dr Hemanta Doloi, 2016)

2) By studying a traditional house and understanding the "Behaviour setting" of a traditional house, i.e., to formulate the elements and components that are necessary to identify it as a typical version, without which the house would not define as a traditional house.(Edward Stack, 1908; Pangcho, 2006; Schoggen, 1989) 


\section{RESULTS}

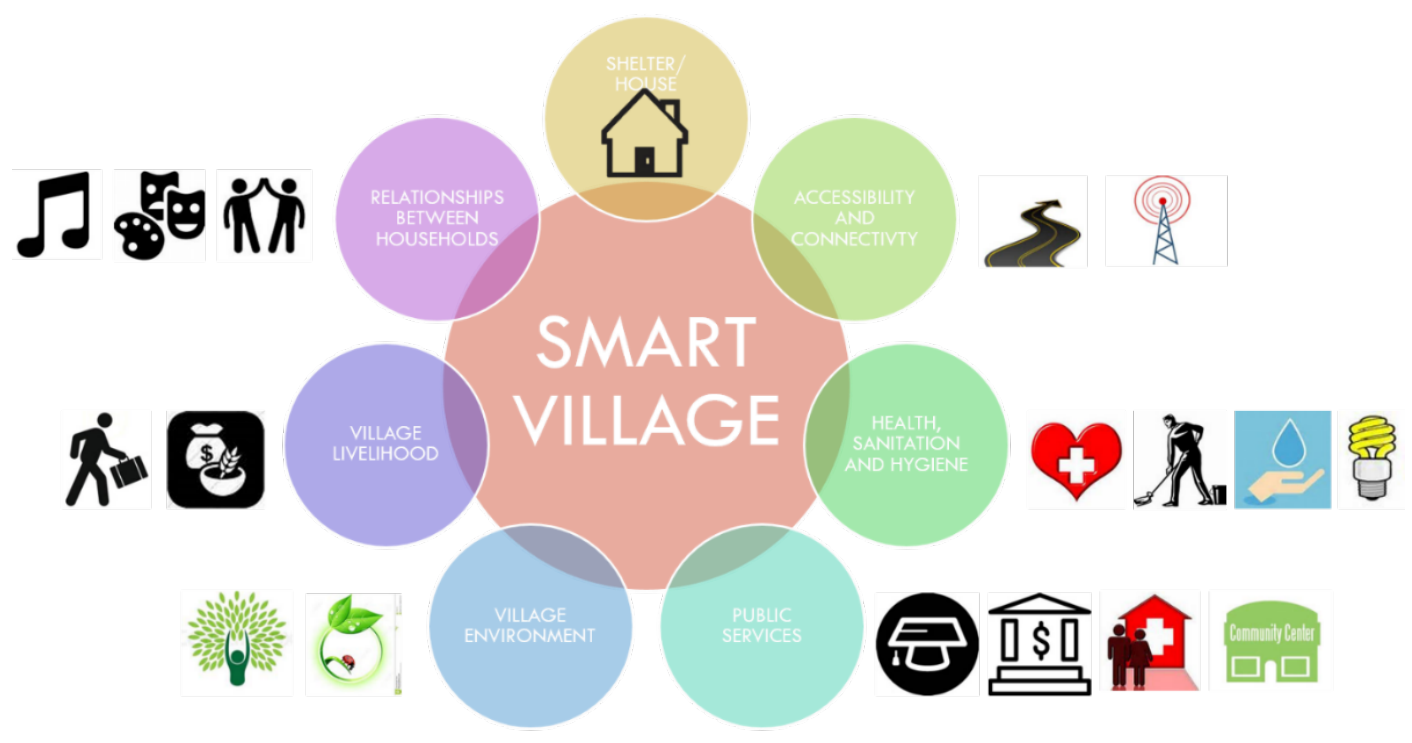

Figure 1 Smart Village components

(Source: Proceedings of the First Workshop on Construction Management and smart villages for Assam, 2016)

Over the first 3 days of the 4-day construction management workshop to initiate and inspire engineering students in AEC, Assam, awareness of their contributions to the rural and less fortunate side of society as professionals, we devised, or in other words, filtered through the possible necessities and components to make up a Smart village.(Dr Hemanta Doloi, 2016)

The categories we arrived at are the following:

\section{Accessibility and connectivity}

Most of the villages do not have proper road accessibility and are not well connected to outside world, even in the local level. Villagers would have to walk or row a boat for hours before reaching the nearest market, school, hospital or bank. There are a few occasions where roads and bridges have been built to connect places to each other as well as to less rural/ urban centres, but the 
lack of maintenance and the erosion due to rain causes problems which almost reverts the built roads to a state of non-existence. Telephone towers are not located in many places and most towns do not have a good network or cell reception, which leads to not having a proper internet connection. In such conditions, quite a chunk of the rural population is cut off from the outside world.

\section{Public facilities: Electricity, Water, sanitation and hygiene}

Lack of electricity reduces the number of hours for productive work, i.e., how long would the men work in the fields, or how long could women grind the flour, etc. While most of these villages are located close to a water source, it cannot be fully determined whether the water source is sanitary and hygienic. Not having proper access makes it difficult for the people to access public health benefits, in terms of medicine and treatment and also education on how to live in hygienic and sanitised conditions. This in turn leads to health problems that people might face due to unsanitary and unhygienic practices.

\section{Public services}

Education is one of the first things that a person from a rural community pursues so that he can start looking for a job with his qualifications to uplift the living conditions of his family and village. There are a few primary schools established in the bigger villages where the children from other neighbouring villages would walk to everyday to be taught by students who have passed the PreUniversity Exams, before they are sent to live and study in the closest town for further education. Having bank accounts and savings, and access to health benefits, are just as rare and difficult due to conditions of the roads.

\section{Village environment}

Every Village has a quality of air or an ambience about it which is unique and is the cumulative result of all the elements in the 
village, from the flora and fauna to the lifestyle of the villagers themselves. In the village political system, the land, environment and people is responsibility of the village headman, and the land and sources are in a way owned by him and his responsibility is to see to the wellbeing of the inhabitants.

\section{Village Livelihood}

Agriculture and Animal husbandry is among the most common jobs or forms of employment and are the main source of income and livelihood for a person from the rural area. Selling the grains, fruits, seeds and meat from their fields and livestock in the closest market, is how they would earn enough to buy other things that would be required by a household. Weaving, carpentry, hunting, pottery and other crafts are skills that do not appear to generate income.

\section{Relationships between households}

There is a certain distance or radius around which villagers set up their homes, depending on the natural environment, the house boundary may be demarcated by bamboo fence or by rocks piled up into walls. Normally the fences aren't as high to keep people out but high enough for animals, so that the occupants of the household is alerted. These low fences allow communication with their neighbours and also a visual connection with further off surroundings.

\section{Shelter/ House}

Everyone needs shelter, from the weather or from animals, an every village has a style that is optimally designed that is suitable to their practices and requirements with respect to the traditions and customs of the culture they follow. The cultural customs and values are highlighted in the way the traditional house is built and how each space is named and demarcated according to the use by the inhabitants. 


\section{The traditional Karbi house}

The typical Karbi house is made of wood, bamboo and hay. The wood is used to make the main basic frame structure on stilts minimum of $2 \mathrm{ft}$ off the ground to avoid animals from entering the house and also as allow storage of wood, bamboo, hay along with the farm animals like pigs and goats underneath. The bamboo is broken, flattened out and interwoven like a mat to make the walls, and floor in the open stilted areas to allow water run-off from washing or rain. The interior flooring is made of wood. The roof is thatched. Mud is occasionally is areas like the fireplace to keep from rest of the house burning down.

The Karbi traditional house has a simple linear plan with an access connecting the front area to the back and separating the private spaces of the house from the public spaces where the guests would normally be received. Guests are not normally let into the house and if in the case of rain, the overhang of the roof around the house is where, they could wait or meet. 


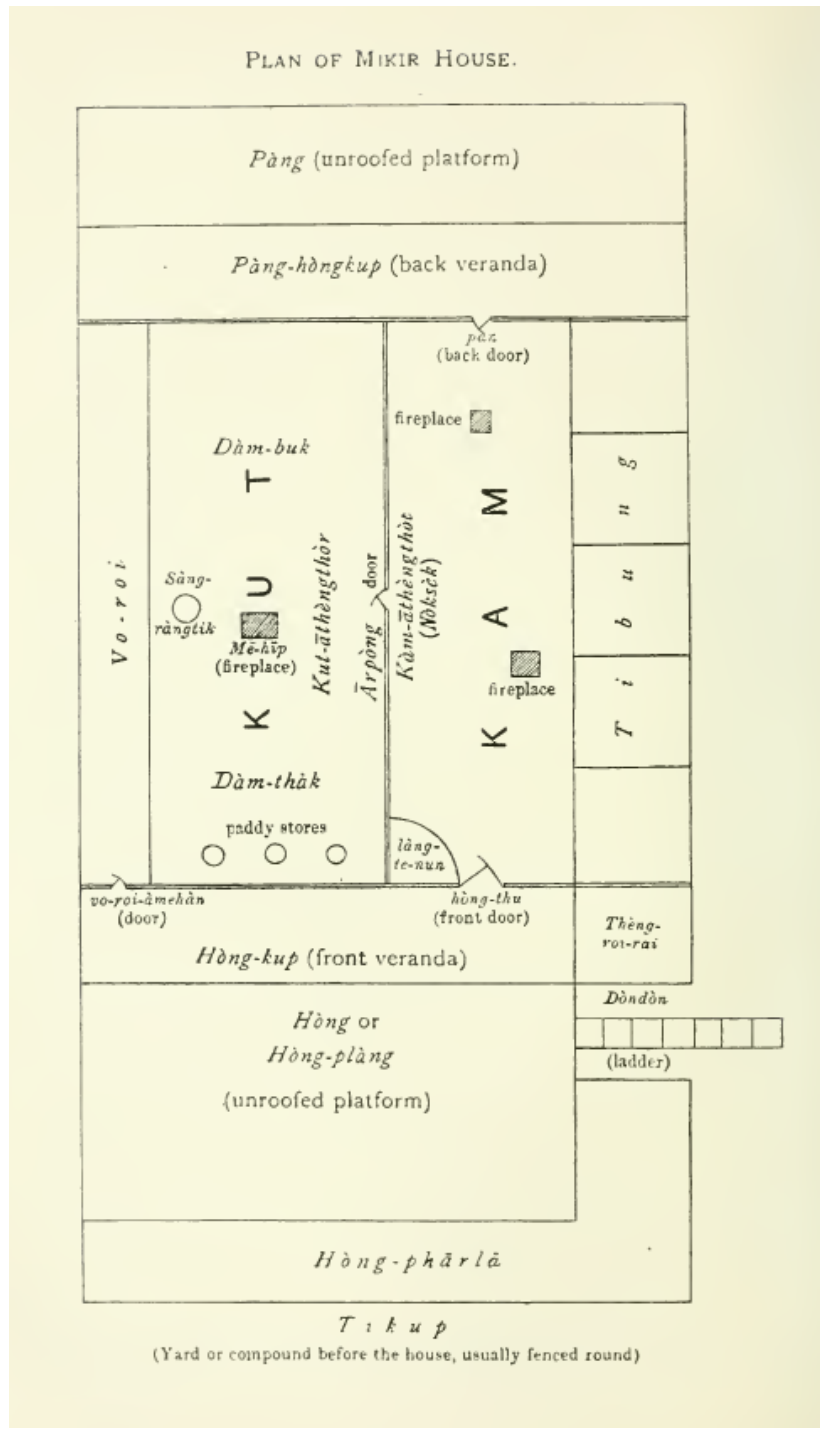

Figure 2 Typical Karbi house

(Source: Edward, 1989)

The traditional house made up of 4 clearly demarcated areas:

- Hong - which is the front veranda or porch. Depending on parts that are shaded or open to sky, the spaces around the Hong have specific uses, such as storage, waiting area, drying of clothes, drying of chillies or other foods. The area opposite to the entry side of the Hong would be wet area 
used for washing and drying of utensils. The area opposite to their main house would have a small shelter built on an elevated platform from the main house. This is rare and is usually just an extension of the house that is meant for guests, but the son and his bride stay there before they move out on their own.

- Pang - which is the back veranda or sometimes a balcony since there was no access from there, and it would mostly be higher off the ground. This area is meant only for females to be used as their private washing and changing area. The handloom would be placed there for the females to weave clothes for the household. It is also used as a nursery during the day.

- Kam - The interior of the house would be primarily divided into 2 areas, the Kam and the Kut, where the Kam is the less private of the two since the access to the pang and the Kut is through it. The area towards the exterior walls and the sloped roof is the Tibung which served as storage for things that would be more frequently used like tools, floor mats etc., or if the couple living in the house had children, they would sleep in the Kam, since the more private area was meant for the Parents, or the eldest couple in the household. It is comparable to a modern day Entry hall or Foyer with sleeping alcoves.

- Kut - The interior most part of the house which was also kitchen area as well as the sleeping area for the eldest couple or parents of the household. It would have only one entry point that would be through the Kam, and though both the Kam and Kut had fireplaces (me-hip), the one in the Kam was meant for cooking while the one in the Kut was only for keeping warm. The household would place the deity or an artefact signifying the deity, on an elevated plank or shelf in the Kam. 
The essential elements that would constitute a Kut would be the main fireplace over which the kitchen utensils would hang on a shelf suspended from the ceiling, and the spices and dried meat would be smoked directly over the fire, to be eaten along with the meals as an accompaniment; a single door for entry and exit to the most private and innermost space within the house; and the placement of the deity in the room which would be on the wall closer to the door. This restricted the access of the children towards the further end of the room which is also the main storage place for things that are considered more valuable like jewellery, rice, etc.

The evening meal would be in a way the most important since that is when all the members of the family would be together at the same time would take place in the Kut. They would sit around the fireplace in the Kut on short stools made of wood, as the mother or the eldest female would serve the food starting from the father or the eldest male. The eldest male of the house hold would take a small portion of the food, mix it together, hold it and give thanks to the deity or to Hem-phu Arnam (Heavenly Father, God of all Karbi as per Karbi religion), then keeping it aside as token for the Deity, or Hemphu Arnam, before eating the meal. After the meal, the male members and the children would continue to sit around the fire, while the females would clean up after the meal, to catch up with each other, tell stories or discuss current events that might have taken place in the village. It is comparable to a family room or a dining room as family members would take the opportunity to communicate.(Pangcho, 2006)

\section{CONCLUSION}

The research executed during the workshop and the traditional House study gives an insight to how customs and traditions practiced by people become the culture that identifies them and 
they identify with that creates connections between people, their house, environment and the village as a whole. Culture is an intangible element, and through this research is intended to attempt to quantify the quality and value that it holds in the life of a person who is of a rural area and how he perceives it, as compared to someone from an urban area.

\section{REFERENCES}

Cambridge, T. C. (2014). Smart Villages Initiative. Retrieved from http://e4sv.org

Doloi, Hemanta and D. D. W. (2016). Growing Capacity in Assam: Proceedings of the First Workshop on Construction Management and Smart Villages for Assam. Paper presented at the Cross-cultural analysis and capacity building in construction management practices focussing $\mathrm{n}$ housing and infrastructure sectors in Assam and Australia, Assam Engineering College, Guwahati, Assam.

Edward Stack, C. L. (1908). The Mikirs. London: Government of Eastern Bengal and Assam.

Pangcho, M. (2006). Retrieved from https://karbi.wordpress.com/

Pasricha, P. (2014). Retrieved from

http://www.lonelyplanet.in/articles/5506/a-day-at-the-

cleanest-village-in-asia-mawlynnong-meghalaya

Samanvay.Com.

Retrieved

from

http://smartvillages.org/Default.aspx

Schoggen, P. (1989). Behaviour Settings.

TheHudliProject. (2017).

Retrieved

from

https://www.thehudliproject.com/

Week, D. (2016). Remote Rural Construction management. Paper presented at the First Workshop on Construction Management and Smart Villages for Assam, Guwahati. 